\title{
HIPOTECAS HUMANAS Y LA RENTA PERMANENTE.
}

\section{José Villacís González ${ }^{1 *}$}

*l Doctor en Ciencias Económicas. Licenciado en Ciencias Políticas. Técnico de la Seguridad Social. Miembro Correspondiente de la Real Academia de Doctores de España. Profesor de macroeconomía de la Universidad CEU-

San Pablo. Mail: villacis.fhm@ceu.es;

*Corresponding Author: -

Mail: villacis.fhm@ceu.es

\begin{abstract}
: -
El consumo ha mostrado su correlación incuestionable con la renta, y Milton Friedman y Modigliani han mostrado y aumentado dicha correlación con su renta permanente. Aquí damos otra versión de dicha renta permanente mediante dos préstamos gigantescos a sectores de la población: hijos y ancianos, que no generan renta pero que la reciben y realizan gastos de consumo. Nuestra segunda novedad es demostrar que estos préstamos son hipotecarios, en los que la cosa que se deja en garantía para la devolución de la deuda son las mismas personas.
\end{abstract}

Palabra's clave: - renta permanente, hipotecas humanas, gasto en consumo, mega préstamos, población activa y población pasiva. 


\section{1.- INTRODUCCIÓN.}

La búsqueda de la renta permanente basada en nuestra teoría de los macropréstamos a los hijos y a los abuelos pensionistas, la expusimos en nuestro artículo: Los Macropréstamos en la Renta Permanente, publicada en International Journal of Business and Management Invention el año 2016. Desde su publicación hasta este artículo hemos reflexionado sobre temas atrevidos y acaso crueles como el lector tendrá ocasión de ver.

Los estudios estadísticos y econométricos han demostrado rigurosamente la relación entre la renta y el consumo. Cualquier otra variable, como la riqueza y el estado de ánimo, es pequeña comparada con la renta. Esto se debe a que el consumo es un hecho social y sobre todo mimético y también lo es la renta, de ahí que ha mostrado su estabilidad ante los ciclos económicos, y por supuesto en condiciones estables. Lo que vamos a exponer es la generación de renta individual y de grupo y la renta nacional, y desde allí en los trasvases gigantes de renta a sectores de la población. Habrá unos factores de producción activos: la población activa, que generan y reciben rentas: flujo monetarios por unidad de tiempo. Esta población activa trasvasa parte de su renta a dos sectores de población. Los hijos y los padres, o sea, los descendientes y los ascendientes, o mejor, sectores que no trabajan. Estos dos sectores son población pasiva.

Esta población pasiva recibe dos rentas; una cada una, y es igual que acaben de nacer o que tengan ochenta años, y ambas gastan en bienes de consumo. Esas poblaciones por consideraciones sociales, sicológicas e institucionales admiten esas rentas como rentas permanentes. Estas rentas que reciben son nuestra renta permanente.

Estos trasvases de renta los consideramos como préstamos, y por su dimensión son gigantes. Y, como todo préstamo, requiere una garantía, una cosa que tenga valor, en este acto financiero las garantías son humanas, son personas: jóvenes y viejos.

\section{2.- Función de consumo.}

La función de consumo que correlaciona la renta con el gasto en consumo en el contexto de la macroeconomía fue descubierta por Germán Bernácer (Alicante- España 1883-1965) en su libro Sociedad y Felicidad. Un Ensayo de Mecánica Social. Establece un crecimiento del consumo menos de proporcional a la renta, lo que se traduce en una curva cóncava al eje de la abscisa-renta. Keynes, el año 1936, en The General Tehory of Employment, Interest and Money, repite este mismo argumento. Parece que es una reflexión sobre el gasto en consumo, si bien, anteriormente, Bernácer otorga una explicación coherente con la formación de producción y el ahorro.

Las funciones de consumo experimentadas o registradas indican unas funciones de consumo estables y con la propensiones marginales decrecientes en sus tramos. ¿Por qué consideramos este decrecimiento en la propensión marginal al consumo? Responder a esta pregunta exige cuestionar o averiguar sobre quién consume, con qué renta, y qué tiempo consideramos.

\section{3.- $\mathrm{L}$ a población activa y la población pasiva.}

Hay dos tipos de población pasiva: los hijos y los abuelos. Nos aproximaremos con nombres y conceptos económicos a estas áreas poblacionales.

\section{1.- Estas dos poblaciones no trabajan y no nos preocupa saber si son o no merecedoras de renta.}

\section{2.-Los descendientes o hijos tienen esta consideración desde que nacen hasta que se incorporan al mundo} laboral y viven fuera de los hogares de sus padres.

Las rentas que reciben de sus padres trabajadores que reciben renta activa, les permite comprarse pañales y gastos en educación entre otros. Habrá pues una estructura por edades y por condición en los gastos de estos jóvenes, y depende de factores como su incorporación al mundo laboral, actitudes, aptitudes, etc. Por ejemplo, los jóvenes norteamericanos vuelan pronto y los hispanos son más inclinados a quedarse en casa.

\section{3.- Los padres, o ascendientes, y que llamaremos con propiedad los jubilados.}

Este término último tiene mucho que ver con dos condiciones complementarias: $1^{\circ}$ haber sido trabajador y por tanto pretérito agente activo y $2^{\circ}$ haber sido cotizante de impuestos sociales. Aquí debemos detenernos para realizar la siguiente aclaración: sea cual sea el régimen de cotización que haya seguido el jubilado: de reparto o de capitalización, la prestación que recibe en forma de pensión, es un flujo de renta actual. Es pues, común equivocarse en creer en una hucha que donde guarda su ahorro dinero el pensionista del que sale su jubilación actual. Este mencionado error consiste en confundir un hecho macroeconómico y contable: las pensiones, con el pacto contractual y/o institucional por el que pagan impuestos sociales para devengar en su día pensiones que es otra cuestión.

Los jubilados reciben su pensión por las transferencias gigantescas, que en muchos países superan cualquier otro gasto presupuestario, de los trabajadores cotizantes.

\section{Notas:}

$1^{\text {o }}$ Hay dos sistema de cotización en la Seguridad Social: uno es el de reparto y otro el de capitalización. El de reparto es aquél por el que un jubilado recibe sus ingresos: jubilaciones, con el flujo de renta actual de la población activa. El sistema de capitalización consiste en el ahorro de una parte de la población activa, normalmente en activos financieros, para recuperarlo íntegramente o en fracciones de renta en la etapa de jubilación.

$2^{\circ}$ Las mujeres, amas de casa, que no se han incorporado al mercado laboral reciben un préstamo. Esto es una verdad a medias, un error, como tendremos ocasión de ver. La mujer es una máquina que tiene el privilegio de fabricar el capital humano. O sea una máquina que produce otra máquina. Esto es una verdad desde el punto de vista de la fábrica 
biológica, y que verá aumentado su valor como educadora en el hogar. Sigue el hecho de que, si no trabaja, es receptora de la renta de la población activa y esta renta es renta permanente.

\section{4.- Préstamos y finanzas nacionales.}

El acto de la producción indica dos hechos que se pueden traducir en tres: uno es el acto físico de la producción en sí. El segundo es el pago que reciben los factores de producción y derivan en seres humanos que reciben una renta. El valor de la producción viene medido por las rentas que se pagan y que es la renta nacional, a las que se añaden los beneficios. El producto nacional, para resumir, es un flujo de bienes y servicios del que derivan el flujo monetario de la renta nacional. Estos son los dos hechos iniciales en la producción. El tercer hecho nace de la capacidad de renta para adquirir la producción de la cual nació.

Esta es la afirmación final de Say de que toda renta genera su propia demanda y que podría decirse que la vocación de la renta consiste en convertirse en demanda. Las fuerzas naturales del sistema consisten en vaciar el mercado. La renta permanente que citamos, y que expondremos, tiene que ver con las siguientes características: $1^{\circ}$ Es una renta que, al margen de su generación y/o evolución, posee internamente unas inclinaciones que tienden a ser constantes.

$2^{\circ}$ Dicha constancia radica en fuerzas humanas, sociales y antropológicas muy intensas. Citaremos en relación con los hijos: el amor y cuidado por los hijos, la inversión en capital humano dentro de la familia con afirmaba Gary Becker (Tratado de la Familia 1981). Con respecto a los mayores: el cuidado y amor a los padres, marco legal e institucional: leyes, constitución, etc.

$3^{\circ}$ Las rentas que se prestan a los hijos tienen constancia debido al techo mínimo de prestaciones que se hacen de cualquier manera y que se convierten en fijos. Lo propio ocurre con los jubilados, quienes reciben rentas constantes a los que se añaden los gastos sanitarios indispensables y sin los cuales habría muertes.

$4^{\circ}$ Las esposas madres de familia, supuesto forzoso en nuestras consideraciones (que luego cambiaremos), administran y reciben una gran parte de la renta de sus maridos activos, para gastos del hogar. Podemos ad hoc hacer una separación de una parte para gastos del hogar y de los hijos por consiguiente, y otra para ellas que gasta en alimentos, vivienda, etc. Estas cuatro características hacen que las rentas recibidas: los macropréstamos, sean estables y determinan una parte significativa de la renta permanente. Y esa renta permanente al ser estable (lo que equivale a ser permanente) tiene por vocación gastarse establemente, con lo que hay una tendencia a que se cumpla la ley de Say.

\section{5.- La hipoteca humana.}

¿Qué es una hipoteca? El Diccionario de la Real Academia Española dice: "derecho real que grava bienes inmuebles sujetándolos a responder del cumplimiento de una obligación dineraria". En nuestro trabajo podríamos afirmar que los préstamos intergeneracionales son créditos que están garantizados con bienes inmuebles en caso de que no se paguen. A nuestros efectos estos préstamos se garantizan con personas. Por eso hablamos de hipotecas humanas. Estas personas son los dos grupos humanos recetores de préstamos y que son: los hijos y los padres jubilados.

Los bienes inmuebles son estas personas. Podemos ampliar este concepto que parece manifestarse con dureza y expresarlo de dos formas.

$1^{\circ}$ La primera es apropiarnos de los sujetos y que entren en la economía como esclavos. El término de esclavos es muy elástico y puede variar desde un jugador de fútbol que se compra, vende y traspasa o se cede a cambio de un dinero, a un esclavo en un taller chino.

$2^{\circ}$ Esta segunda es interesante. Se negocia con la persona hipotecada (insistimos: como persona), y le compramos su producción futura. Esta afirmación es la preferida por Becker, aunque él no la exponga de esta manera contractual. Estamos formando capital humano para que sirva después para generar producción. En términos financieros, el sistema les presta a los jóvenes, lo que supone una creación de un derecho o activo financiero. Cuando se incorporan al mercado de trabajo, le compran su producción con los activos financieros generados en el periodo anterior.

Cobrarse una hipoteca en un anciano que no es productivo exige un mayor análisis. Veamos por qué no es apto fijarse en él como hipoteca humana: primero porque no es productivo por dos motivos: Primero, no se encuentra en el mercado de trabajo. Segundo, está obsoleto. ¿Entonces cómo lo cobramos?

Un cobro es un intercambio de activos: uno que es el dinero y otro que es parte de la producción nacional, o bien dinero a cambio de un activo financiero. Si el jubilado cuando era trabajador activo, prestó dinero a unos jubilados, generó un activo financiero institucional en el periodo t. O sea que tiene un derecho de cobro legal e institucional y, cuando pasa a la reserva en el mercado de trabajo, compra con dicho activo del periodo t-1, la producción del periodo $t$.

Con todo, habría que añadir en este último caso ciertas interferencias interpretativas: el trabajo no remunerado de los ancianos: cuidado de nietos, arreglos de la casa, etc. y gastos muy elevados en asistencia sanitaria, cuidado del Estado, etc.

\section{6.- La hipótesis de consumo del viejo filósofo o teoría del ciclo vital de Modigliani ,.}

Modigliani hace referencia a la renta permanente con algo parecido a la renta de toda una vida e igualmente con el consumo de toda una vida. Afirma que la renta permanente es la que se recibe durante toda su vida: YD y que se relaciona con el gasto en consumo de toda su vida CV. Visto así

$$
\mathrm{CV}=\mathrm{f}(\mathrm{YV})(1)
$$

El sujeto, afirma, distribuye su renta de manera que sea homogénea a lo largo de su vida y, de acuerdo con ella, realiza un consumo también homogéneo. A lo largo de la vida, el consumidor tiene una etapa en la que obtiene más renta de 
lo que planea consumir y que se corresponde con la etapa del ahorro. Habrá otra etapa en que consumirá una cantidad superior a su renta, y que es el desahorro y que es la etapa de jubilación.

Esta hipótesis o teoría es tan racional que más parece que emana de un filósofo, y que sea viejo, que de un sujeto productivo que vive el día a día. Daremos las razones por las que no estamos de acuerdo: Es un filósofo porque contabiliza y reflexiona sobre variables ya registradas: renta y consumo de toda una vida. Estas conexiones internas pueden encontrase en nuestro trabajo sobre hipotecas humanas, sin que nosotros encontremos planifiquemos hacia atrás ni dichas rentas ni dichos consumos. Sin embargo, como veremos más adelante, nuestras crueles hipótesis devendrán patrones de consumo similares a la renta y consumo vital de Modigliani.

Hemos indicado que la teoría del consumo vital de Modigliani se parece a las reflexiones de un filósofo viejo. Visto ya lo de filósofo, veremos qué es lo de viejo. Este economista o sujeto planea su renta vital y su consumo vital, no en un momento en concreto, que sería lo juicioso, sino a río pasado. No es un plan por periodo de recepción de renta y de ejercicio de gasto, sino una contabilidad o ejercicio ex post de hechos pasados propios de un anciano que se retira a reflexionar sobre hechos pasados, que renta recibió y que hizo con ella. Como tendremos ocasión de apreciar, nuestra renta permanente es real y percibida como tal en cada periodo en concreto, y periodo tras periodo. Cada sujeto es diferente de otro, y en nuestro caso se dividen en dos los personajes: los trabajadores en activo de cada periodo, y los pasivos que son los que reciben los mega préstamos y que son los hijos y los jubilados.

\section{7.- La renta permanente de Milton Friedman. Un sencillo error.}

Friedman divide a la renta en dos partes: una que es la transitoria y otra que es la permanente. Económica y subjetivamente la renta permanente es aquella que se considera más o menos fija siendo el caso más típico (a nuestros efectos) el sueldo de los funcionarios del Estado. El consumo se ajusta fijamente a este tipo de renta que será permanente. Si por el contrario, el sujeto, pongamos por ejemplo un obrero de una fábrica de automóviles, empieza a recibir unas pagas extras porque la empresa decide aumentar transitoriamente sus stocks, esta es una paga transitoria que no tiene por qué afectar al consumo, o no al menos totalmente.

Aparte de que según nuestra consideración, la renta transitoria sí que afectará algo al gasto en consumo, nuestras afirmaciones se ceñirán a una renta permanente al estilo Friedman, pero diferentes de raíz, sobre todo estableceremos una diferencia entre renta transitoria y permanente.

Queremos decir que nos preocuparemos en definir la renta que es o no es permanente a partir de los mega préstamos que se hacen a los hijos y a los jubilados. Veremos que toda renta se define por las siguientes características:

1.- Por nacer de la producción del periodo.

2.- Por ser periódica.

3.- Por buscar periódicamente la producción de consumo de la cual brotó.

4.- Por eludir las fluctuaciones de la renta.

\section{8.- Comparación de otras teorías del consumo con la función de consumo de Bernácer.}

La función de consumo de Bernácer del año 1916 (libro: Sociedad y Felicidad. Un Ensayo de Mecánica Social), como vemos en el gráfico 1, se caracteriza porque nace de la producción, y evoluciona según su sentido. Nace y termina en cada periodo siguiendo un dinámico artífico expositivo período tras período.
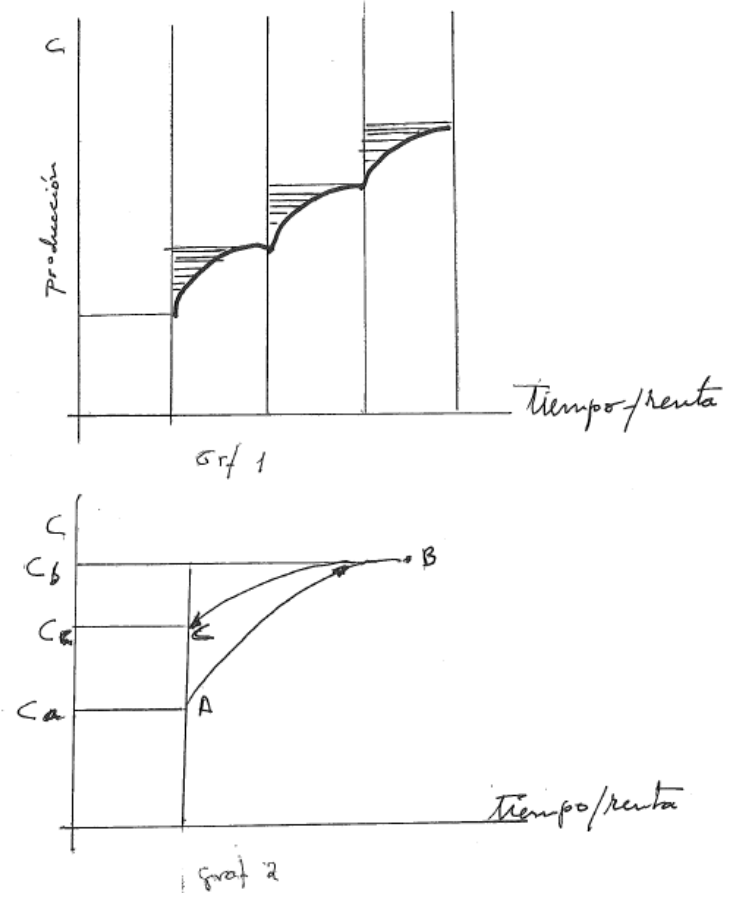

Bernácer cuenta con los deseos de consumir pronto y de acuerdo con las necesidades que son crecientes y que son, en general, resultado del progreso social. Habrá una tendencia natural a devorar la producción y a acabarla, sino fuera por la tendencia creciente a producir. De modo que el gráfico 1, con mucho sentido común, expresa en el eje vertical la 
tendencia al aumento de la producción y el consumo, y por otra parte en el eje de las abscisas el tiempo en que tiende a absorberlo. Del gráfico $1 \mathrm{y}$ de los argumentos se aprecia que frente a la tendencia vertical a la producción, el consumo lo hace menos que proporcionalmente. Resumiendo, siempre habrá una competencia o una tensión entre la producción y el consumo por alcanzarla. La diferencia es el ahorro representada en las áreas sombreadas.

La siguiente afirmación de Bernácer, igual que las anteriores, define a nuestros efectos, la tendencia natural en que la renta sea permanente y periódica. Si acaso la producción no crece y se estanca, y sobre todo si disminuye como en una depresión, se gasta el ahorro acumulado para sostener el consumo. En realidad, una contracción de la renta, no será seguida necesariamente por una disminución del consumo de valor absoluto igual sino algo mayor. Queremos decir que el camino de ida hacia arriba del consumo no tendrá el mismo valor absoluto que el de vuelta.

En el gráfico inferior (gráfico 2) se aprecia como el consumo crece desde el punto A hacia el punto B, pero, al contraerse la renta, el consumo no desciende por el camino por donde subió, o sea que no vuelve hacia el punto A, sino hacia el punto $\mathrm{C}$, el cual es inferior al consumo en B, pero superior al gasto en consumo del punto A. Lo expresamos según las siguientes desigualdades:

$$
\mathrm{Ca}<\mathrm{Cb}<\mathrm{Cc} \mathrm{O} \text { sea que } \mathrm{Cc}>\mathrm{Ca}
$$

\section{Nota: esta es la explicación de Bernácer. El gráfico 2 es elaboración propia.}

Este fenómeno estudiado por los sociólogos se debe principalmente a que el placer instalado en el consumo se resiste a abandonar sus hábitos, y al efecto de imitación de los consumidores en guardar las apariencias. Aquí tenemos una explicación, una más, que demuestra que el consumo es estable y sólido o cohesionado, y que tal efecto proviene de una renta permanente diferente a las de Modigliani y Friedman.

El análisis de Bernácer contempla una sucesión de hechos presentes, muy cercanos en la cadena de ayer, de hoy y mañana, y que descansa en última instancia en gastar lo que llega, sin preocuparse por la eternidad de la existencia propia (Modigliani) ni tampoco por las fluctuaciones de una renta que se supone transitoria (Friedman).

\section{9.- Nuestra renta permanente.}

La renta periódica de la población activa (la bernaceriana) se presta -como hemos indicado- a dos grandes sectores de la población: los hijos y los jubilados. Tal como se aprecia en el gráfico 3.

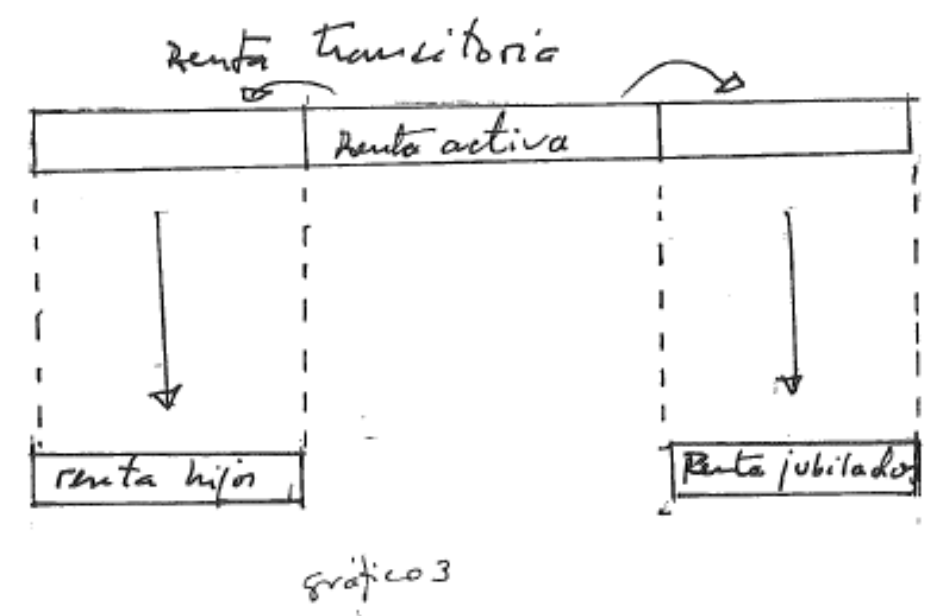

La barra superior es la renta ganada por los agentes productivos. Dicha renta que es la del periodo, sea cual sea su condición, es nuestra renta transitoria. Dicha renta transitoria es la efectiva, o sea la recibida, y veremos como el conjunto de la economía la transforma en permanente.

Para que una renta transitoria se transforme en permanente hacen falta dos condiciones:

La primera consiste en considerar el trasvase a los dos sectores de población y que consiste en préstamos hipotecarios que son préstamos hipotecarios humanos porque el bien que se deja en hipoteca son seres humanos: hijos y pensionistas.

La segunda condición consiste en hacer entrar una serie de factores que definen a cada sector de la población.

Con respecto a la primera condición existe una proporción más o menos fija demográfica a corto y medio plazo de estancia en los hogares de los hijos. Por otra parte los ancianos crecen en proporción también fija en el sistema. Estas proporciones estables inducen a un trasvase de rentas transitorias hacia esos dos megasectores de la población: hijos y abuelos (pensionistas). Queremos decir que existe una llegada de rentas (préstamos) hacia estos dos sectores que es más o menos fija, y que por tal situación genera unas expectativas estables en los receptores de 
dichas rentas. Estas expectativas estables convierten a las rentas transitorias en fijas, aunque existen otros argumentos adicionales según sea el sector de la población.

Analicemos cada uno de ellos.

\section{1.- Los hijos.}

Habrá unos gastos estables y que convierten en estables las rentas recibidas transitorias, como tendremos ocasión de apreciar: por ejemplo, los gastos en pañales, en alimentos, en estudio. No podemos alterar el hecho de que un niño no gaste en pañales o en alimentos, y que dichos gastos, y por tanto la renta de donde provienen, sea estable y se configuran como renta permanente. O lo que es lo mismo: la proporción entre dichos gastos y la renta recibida es estable. Es una estructura de la civilización, o si se quiere, un parámetro social.

Pero el principal argumento de gasto y por tanto de renta en los préstamos a los hijos es la inversión en maquinaria humana, según economistas como Gary Becker. Tanto los padres como el Estado (o sociedad) consensuan en la inversión en maquinaria humana. Este argumento contundente precisa de una renta que llega bien en su mayor parte dentro de los hogares, o bien fuera, proveniente del Estado. Dicha renta, que hace posible dichas inversiones, es considerada como permanente, entre otros motivos, porque no es fácil desviarla de su cauce: crecimiento normal o estable.

La inversión en capital humano no es el único argumento principal que determine o no la renta y el gasto. Hay otro argumento como es el hecho de que los padres expulsen a sus hijos de sus hogares cuando se encuentren en condiciones de trabajar. Esto tiene varios fundamentos y depende mucho de la cultura social de cada país. Sacar a un hijo del hogar significa interrumpir el préstamo, o sea una transferencia de renta y ello condiciona el gasto en consumo en ese sector de la población. Desarrollaremos estos argumentos. Un hijo y sus hábitos pueden ser incómodos y el padre considerará adecuado expulsarlo si sus costumbres no son las correctas y afectan al hogar negativamente. El desorden, las drogas, la violencia, aconsejan a los padres a la expulsión de los hijos, incluso antes de que cumplan la mayoría de edad. Otro argumento consiste en empujarlos fuera para que tomen la iniciativa en la lucha por la vida. Aquí habrá, después, una renta permanente diferente y un consumo diferente. No será lo mismo un consumo dentro del hogar que fuera de él.

Por el contrario puede haber una dilación en la vida dentro del hogar, o bien dentro del amparo económico, aunque físicamente estén fuera del hogar. El ejemplo más evidente son los estudios universitarios, en especial las carreras técnicas de larga duración. El argumento expuesto en líneas anteriores, se refiere al capital humano o inversión humana. Aumentará, en este caso, el préstamo intergeneracional. Y como en el presente trabajo, nos referimos a la hipoteca humana, o sea al ser humano como garantía del cobro de la hipoteca, el hijo pasará a ser el agente que devuelve al sistema, lo que se ha invertido en él.

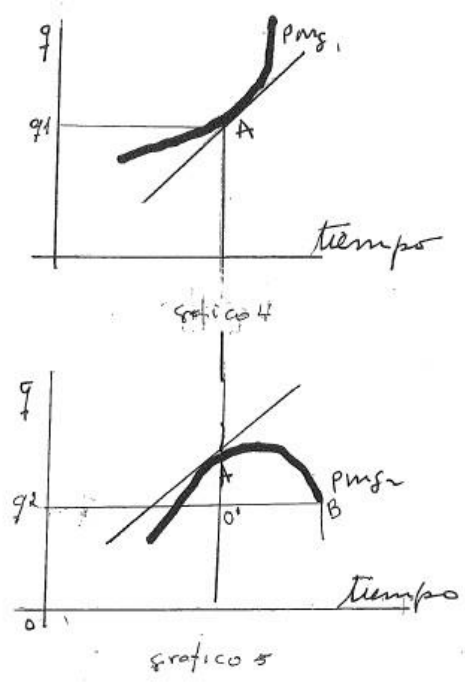

En el gráfico 4 apreciamos que los jóvenes, sin salir del hogar van acumulando energía potencial productiva. El paso a la adolescencia y desde allí a la mayoría de edad, hace que el rendimiento social como ciudadanos y desde luego como agentes productivos, genere incrementos en dicha producción por unidad de tiempo. Esto se aprecia en nuestra curva de productividad marginal, en la que destaca el punto A que es cuando se empina la curva hacia arriba. Representa un repunte de la productividad marginal.

Este punto, como veremos en adelante, es un aumento en la productividad marginal social, y marcará el punto en los hijos en que quedará interrumpida la recepción de préstamos, y dejarán de ser parte de la población pasiva. A nuestros efectos, pasarán de ser receptores de préstamos a ser generadores de préstamos.

Vayamos a otra consideración, esta vez, brutal. Un joven independizado y capitalizado (factor capital) tendría como esclavo un gran valor. Su valor como esclavo tendría dos componentes muy positivos: Uno su elevada productividad marginal, basada en sus conocimientos técnicos y como ciudadano etc. Otro, la dilatada esperanza de vida, esto es, la larga serie de productividades marginales. Es por este motivo, caeteribus paribus, por lo que cuesta mucho comprar a los grandes esclavos como son las grandes figuras del fútbol, del baloncesto, etc. 


\section{2.- Los abuelos o jubilados.}

Son personas que bajo consideraciones de edad, productivas, institucionales, han pasado una frontera que los coloca fuera del mercado de la producción. Queremos decir que no son la población activa. Estas consideraciones son, muchas de ellas, convencionales. No obstantes queremos hacer las siguientes matizaciones.

La expulsión del mercado productivo se debe a que físicamente no rinden los periodos de producción que se consideran normales (otra convención). También bajo la dimensión intelectual, y esta última se debe a dos causas:

Primero, el rendimiento marginal decreciente, o sea la productividad marginal del día a día del vigor mental.

Segundo, la obsolescencia del capital humano que no se asimila los avances de la tecnología. Esto, a su vez tiene dos componentes. Uno, en que la capacidad del capital humano, entiéndase el ser humano, no es capaz de asimilar la nueva tecnología. Otro, que carezca de ánimos y voluntad para estar al corriente de las nuevas tecnologías.

Un argumento, no débil, es el que expresa el camino de ida sin retorno. Queremos decir que en un anciano, en cuanto deja de trabajar, envejece técnicamente muy deprisa, y le resulta en extremo difícil volver al nivel de producción (productividad marginal) anterior. Esto es lo que llamamos camino de ida sin retorno.

Debido a grandes fenómenos contractuales políticos e institucionales (Constitución, leyes, sindicatos, etc.) se admite el cansancio de aquellos que durante gran parte su vida fueron población activa. Estos contratos son muchas veces coercitivos, y colocan periódicamente a ingentes masas poblacionales como población pasiva.

Esta población anciana deja el mercado laboral y también su condición de prestamistas de su renta transitoria, y pasan a ser receptores o prestatarios.

No solamente son las condiciones megacontractuales que los hace mutar de población activa a población pasiva o jubilados, sino las fuerzas inerciales del sistema en el mercado de trabajo y de productos finales que los arrincona.

Un trabajador o un esclavo, si se quiere, vale en el mercado de compraventa su producción marginal. Mejor sería decir que vale la actualización de la cadena de rendimientos marginales. Hablando con crudeza, la venta de un esclavoanciano, sería cero, ya que nadie querría comprarlo. Es más, ni siquiera sería aceptado como regalo. El gráfico siguiente (6) expresa su rendimiento marginal.

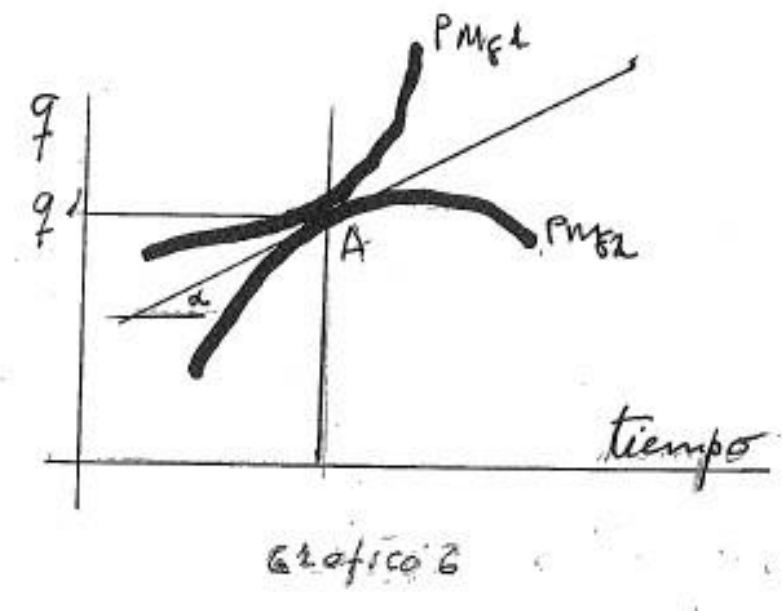

Hay dos zonas en la curva de productividad marginal de un ser humano ex post su vida laboral. Uno anterior en que su productividad marginal crece, y que corresponde con su vida profesional. Otro, es cuando su rendimientos marginales (productividad marginal) es decreciente, y esta última se corresponde en su etapa pasiva receptora de préstamos. El punto A, es aquel que divide a las dos zonas: la de productividad marginal creciente y la decreciente.

Nota: De cualquier forma este tipo de análisis no tiene en cuenta la productividad marginal endógena, que se produce dentro de la familia. El cuidado de los nietos, labores caseras, asesoramiento informal como miembro del consejo de ancianos. Y todas ellas, siendo valiosas, no son recogidas en el flujo de la producción nacional o PIB. Por otra parte, el descanso de los ancianos debería tener en cuenta otros ingredientes contractuales como es la compasión.

No queremos evitar otras vertientes de los argumentos debido a estimaciones subjetivas, cuando todo análisis debe admitir toda la verdad y nada más que la verdad. Nos referimos al suicido. El análisis neoclásico y su adjunto el marginal, admite al sujeto como productor y consumidor como único juez, sin admitir las economías externas positiva o negativas. La realidad social es integral, queremos decir que los ancianos se conectan a través de su conciencia con el grupo social al que pertenecen. En muchas culturas, sobre todo las anteriores al mundo contemporáneo (guaraníes en 
Paraguay, esquimales), algunos ancianos se apartaban del mundo para aliviar la carga que representaban a su grupo. En otras palabras, no recibían los préstamos reales para que estos los recibiesen íntegros la población activa (cazadores, etc.)

\section{3- La renta que recibe un anciano, la jubilación, es considerada por él y por el conjunto de la economía, como renta permanente. Vemos por qué. Hemos visto que los mega préstamos para transformarse por los receptores como renta permanente, deben reunir dos requisitos:}

Primero. La renta transferida y que pasa a ser recibida como pensión de jubilación, se mantiene o recibe en proporciones constantes, de acuerdo con los criterios rígidos de los Estados. A veces, estas constancias se alteran debido a circunstancias extravagantes como son las hiperinflaciones, como, por ejemplo, cuando los precios suben un $1000 \%$ mensual. Lo que también importa en estos juicios es que dichas jubilaciones que son permanentes son financiadas con tipos impositivos más o menos constantes o permanentes.

Segundo. Circunstancias personales de un anciano al que se le supone sabiduría. Se sabe vulnerable tanto por su mayoría de edad como por su frágil situación económica.

Estos dos requisitos modulan la renta nominal, o la renta transitoria prestada en renta permanente.

\section{0.- El gran pacto.}

\section{1.- La igualdad de las productividades marginales.}

Las fuerzas naturales del mercado de trabajo y las institucionales de forma natural (la primera) y empujadas (las segundas) llegarán al punto de equilibrio. Todo ello depende de quién tratemos: los hijos o los jubilados.

Con relación a los jóvenes próximos a la libertad, las fuerzas de mercado estrictamente económicas excitadas desean incorporar a los agentes productivos que sean eficientes, y estos son los jóvenes que son atractivos tanto por su vigor físico como por la tecnología endógenas que llevan incorporados. Esto último se refiere al capital humano. Hay otros factores como las fuerzas institucionales que los frenan o los asimilan, como puede ser la incorporación al ejército o a la administración delEstado.

Este punto de liberación se logra económica y socialmente en el punto A de su productividad marginal de los jóvenes. Gráfico 4. Este punto lo asociamos, aunque no rígidamente, con el óptimo técnico de las funciones de producción.

En los ancianos hemos dejado indicado que se encuentra en el punto A de su productividad marginal (gráfico 5), y que podremos asociar como el máximo de la producción, punto a partir del cual la producción es decreciente.

Observamos (gráfico 6) que ambas curvas se tocan en el (los) punto(s) A, en que tienen la misma productividad marginal. Este es el punto de equilibrio social y económico y tiene una explicación específica según hemos explicado en el apartado 9. El sistema de producción (las empresas) compra o incorpora a un volumen de jóvenes fuertes y capitalizados hasta un volumen q1 en que es óptima su producción. Esta incorporación de nuevos trabajadores al mercado de trabajo vendrá equiparada con el mismo volumen de trabajadores viejos eliminados de dicho mercado.

Esto es lo mismo que decir que nuevas y crecientes productividades marginales compran y neutralizan a las productividades marginales decrecientes de los viejos. Y para argumenta mejor, nos diremos ¿para qué comprar y neutralizar productividades marginales decrecientes, si es posible quedarnos atrás? $\mathrm{O}$ sea, es mejor no sobrepasar el volumen de producción del punto A que es común en los viejos y ancianos. El punto A (gráfico 6) representa aquél volumen de producción óptimo y aquel volumen de trabajadores eficientes.

\section{2.- La equivalencia de los préstamos.}

\subsection{1.-Equivalencia con los ancianos.}

El punto A del gráfico 3 representa un volumen de nuevos trabajadores y de nueva población pasiva y de igualdad en las transferencias de productividades marginales. Fundamentalmente representa una nueva masa poblacional que vía impuestos (estables) realizan nuevos préstamos: pensiones a una nueva población pasiva los jubilados recientes. En un marco económico e institucional a corto plazo y estable, no habrá nuevos mega préstamos en el sistema: unos dejan de pagar dichos impuestos (los ancianos), pero también ingresan unas pensiones. Es difícil evaluar o comprar los impuestos sociales a la Seguridad Social con el volumen de pensiones recibidas.

\subsection{2.- Equivalencia con los hijos o descendientes.}

Es difícil evaluar el porcentaje de hijos nacidos antes de la independencia económica de sus padres y los que han nacido después de dicha independencia, pero es razonable concluir que los jóvenes tienen hijos una vez emparejados y con un trabajo. Los nuevos trabajadores empiezan a generar préstamos a dos sectores de población: a sus hijos, principalmente en comida y pañales, y a los nuevos ancianos, que reciben nuevas pensiones.

\section{0-2-3.- Visón de conjunto a corto plazo de las hipotecas humanas}

Pero todo este flujo financiero debemos considerarlo en una situación temporal a corto plazo que no contemple nuevas masas poblacionales en creación (súbitas inmigraciones) destrucción (guerras) o innovaciones tecnológicas.

Insistimos en dos hechos en los cuales ya hemos trabajado: llegan nuevos hijos (población pasiva reciente) y también es cierto que habrá nuevos padres (jóvenes) que trabajan y que dejan de percibir préstamos. Aquí habría un stock humano poco variable a corto plazo que no altera el flujo de mega préstamos netos. Estos nuevos préstamos cuyas hipotecas están garantizadas con seres humanos es lo mismo entregar a los prestamistas acreedores a los nuevos trabajadores o el flujo de producción actualizado.

Otro acontecimiento: Llegan trabajadores que se convierten en pasivos: jubilados que reciben pensión. Como otros 
desaparecen por agotamiento biológico y muerte, este grupo, a corto plazo no se altera. Los que desaparecen dejan de cobrar pensión y los nuevos si la cobran, por lo que es de estimar que, a corto plazo, no habrá un aumento neto de población anciana.

Nota: a largo plazo, la realidad nos demuestra un hecho que preocupa en extremo. El aumento de la población pasiva, y por consiguiente de los préstamos en forma de jubilaciones, y la disminución de los descendientes o hijos, con lo que se altera la relación: población activa/población pasiva.

Toda esta argumentación nos priva de poder responder del cobro de la hipoteca humana en los ancianos. Podríamos preguntar también qué hemos hecho con los nuevos trabajadores, cómo cobrar la hipoteca en los ancianos. Es lo mismo que preguntar y responder si es igual comprar físicamente al anciano esclavo que comprar la cadena de sus productividades marginales. Desgraciadamente, habrá una frustración social, ya que ninguna de esas dos posibilidades es factible. Nadie los requiere. Los ancianos no se pueden ni vender ni comprar.

\section{1.- Un inventario sobre la renta permanente.}

Veamos el gráfico 3. La barra superior en toda su extensión es la renta transitoria o sea la renta nominal que recibe la población activa por participar en la producción. De allí salen dos préstamos hipotecarios: uno a los descendientes en la barra inferior- izquierda y otra en la parte inferior derecha que son los préstamos a los ancianos. Ambos préstamos, que reciben una gran parte de la población, se modulan como rentas permanentes por razones sociales, sicológicas, económicas, demostradas cotidianamente.

Esto quiere decir que las dos poblaciones pasivas - hijos y abuelos- transforman la renta transitoria de la población activa en renta permanente. Nos queda por estudiar la renta activa de los trabajadores, o sea, el total de la transitoria después de los préstamos. ¿Cómo saber, como hacen Milton Friedman y Franco Modigliani, si la renta que genera y transforma la población activa es renta permanente? Siguiendo el gráfico 1, el razonamiento de Bernácer, se debe considerar el periodo total como una integral de sub periodos, y allí se manifiesta una correlación muy estrecha entre renta y consumo. Esto nos lleva a considerar que en una elevada proporción, cercana al cien por cien, dicha renta es permanente. Esto se ve apoyado tanto, como afirmamos, que, incluso, ante variaciones de la renta, el consumo hace esfuerzos por permanecer estable. Y solo es posible si en la mente de los trabajadores activos y mejor en el grupo social en conjunto habita la renta permanente.

Un argumento adicional consiste en saber que la renta transitoria de la población activa no es esquivada para el gasto, ya que debe transmitirla a los hijos y a los abuelos. Esta transferencia de préstamos es permanente.

\section{1.- Resumen.}

El centro del trabajo es definir la renta que se considera como permanente en el consumo. No hay otra solución que admitir tres grupos receptores de renta: uno receptor neto por participar directamente en la producción y que es la población activa que recibe el total de la renta nacional. Esta es la renta que llamamos transitoria y que devendrá en renta permanente.

Este paso es posible si tenemos en cuenta otros dos receptores de renta y que son dos gigantes grupos de población: la población pasiva de los hijos, y la población pasiva de los abuelos o jubilados. Hemos considerado las transferencias de renta como mega préstamos con garantía humana, o sea, hipotecas humanas. Por la proporción estable en que se reciben y por su asimilación como sujetos pasivos, estos dos préstamos se convierten en rentas permanentes. Lo que queda después de los préstamos es la renta transitoria de la población pasiva, que queda transformada en renta permanente.

Por tanto, nuestro análisis es real y a corto plazo, y rechazamos los estudios contables estadísticos que correlacionan conductas extrañas, como que los vaivenes de la renta transitoria no se traducen totalmente en el consumo.

\section{Términos y conceptos:}

Renta permanente. Renta transitoria. Hipoteca. Megapréstmos hipotecarios. Conversión de renta transitoria en renta permanente. Capital humano. Inversión humana. Gasto en pañales. Productividad marginal en jóvenes y en ancianos.

Pensiones. Dilatación de la vida en familia. Expulsión de la familia. Suicido social. Cadena de rendimientos.

\section{Referencias bibliográficas y correspondencia.}

[1].Barro, Robert and J. Becker, Gary (1988): "A Reformulation of the -Economic Theory of Fertility." Quaterly Journal of Economics 103 (Febrero): 1-25.-

[2].Barsky, Robert and Miron, Jeffrey (1989). "The Seasonal Cycle and the Business Cycle.” Journal of Political Economy , 97 (junio): 503-534.

[3].Becker, Gary S., Murphy, Kevin M. and Tamura, Robert. (1990). "Human Capital, Fertility and Economic Grow." Journal of Political Economy 98.

[4].-1991. "A Teatrise on Family". Harvard University Press.

[5].Bernácer, Germán (1916): “Sociedad y Felicidad, Un Ensayo de Mecánica Social”. 85 -

[6].88. Editorial Beltrán, Madrid.

[7].-1925 "Interés del Capital. El Problema de sus Orígenes,” Editorial Lucentum.

[8].-1934 “Génesis y Peripecias del Ahorro". En la Revista de Economía Española. Madrid.

[9].Bryant, John (19839: ”A Simple Rational Expectation Keynes Type-Models.” Quaterly Journal of Economy 98 (agosto). 
[10]. Campbell, John y., and Cochrane, John H. (1999): "By Force of Habit.A consumption- Based Explanation of Aggregate Stock Market Behavior.” Journal of Political Economy 107.

- 1989 "Consumption, Income, and Interest Rates Reinterpreting the Times Series Evidence." NBER. Macroeconomic Annual 4.

[11]. Deaton, August (1991: "Saving And Liquidity Constraints" Econometrica 59.

[12]. -1992 "Understanding Consumption." Oxford University Press.

[13]. Friedman, Milton (1957): “A Theory of the Consumption Function”. Princeton University Press. Princeton.

[14]. Kimball, Miles S. (1990): "Precautionay Saving in the Small and the Large." Econometrica 58 (enero). 52-72.

[15]. Lucas, Robert E.1972. "Expectations and the Neutrality of Money.” Journal of Economy Theory. 4 (abril).

[16]. -1973. "Some International Evidence on Out-put-Inflation Tradeoffs." American Economic Review. 63

A. Modigliani, Franco (1963): "The Life Cycle Hypothesis of Saving", en colaboración con Ando, American Economic Review..

[17]. -1963: "The Monetary Mechanism and its Interaction with Real Phenomena", REStat.

[18]. -1968: "Life Cycle, Individual Thrift and the Wealth of Nations", American Economic Review.

[19]. -1968 : "The Role of Intergeneration Transfers and Life-Cycle Saving in the Accumulation of Wealth", 1988, JEP.

[20]. Shea, John. (1995): "Union Contract and the Life Cycle/Permanent-Income Hipothesis." American Ecomic Review 85 (marzo).

[21]. Sauleles, Nicholas S. (1999): "The Response of Household Consumption to Income Tax Refunds." American Economic Review (septiembre).

[22]. Villacís, José: Los Macropréstamos en la Renta Permanente, en International Journal of Business and Management Invention.

[23]. Weil, Philippe (1990): "Nonexpected Utility in Macroeconomics.” Quaterly Journal of Economics 105 (febrero).

[24]. Zeldes, Stephen.(1989): “Consumption and Liquidity Constraint: An Empirical Investigation.” Journal of Political Economy, 97 (abril).

\section{Correspondencia:}

Franco Modiglian: 16-6- 1999.Tema: Comentario macroeconómicos.

- 2412 1999. Tema: comentario a la identidad multiplicador de la renta y velocidad renta del dinero.

James Tobin: 21 de junio de 1985. Tema: conocimiento de la obra de Bernácer.

- 13 de mayo de 1997.Tema: crítica a la igualdad entre el multiplicador de la renta y la velocidad renta del dinero.

Paul A. Samuelson: 14 de julio de 1999. tema: macroeconomía.Germán Bernácer.

- $\quad 24$ de junio de 2002. Tema: crítica a la identidad entre el multiplicador de la renta y la velocidad renta del dinero.

Lucas Robert E. Charla-conferencia del profesor Robert E. Lucas sobre los efectos de la política monetaria en la Universidad CEU San Pablo. Preguntas formulas sobre los efectos a largo plazo de la renta. 